\title{
The Association between Age and Depressive Symptoms among Older Men and Women in Europe. Findings from SHARE
}

\author{
Isabella Buber, Henriette Engelhardt
}

\begin{abstract}
Empirical evidence of the effects of age on depressive symptoms is mixed, ranging from positive to zero to negative effects, depending on the modelling of the age-depression profile. This paper uses internationally comparative data to analyse the association between age and the prevalence of symptoms of depression, controlling for well-known determinants of mental health. Based on the first wave of the Survey of Health, Ageing and Retirement in Europe (SHARE), depressive symptoms of 28,538 persons aged 50 to 89 from eleven European countries and Israel are analysed using a negative binomial regression model. The results indicate that the number of depressive symptoms measured by EURO-D scores increase with age and are higher among women than among men. When including socio-demographic characteristics, health conditions and economic strains, the association between depressive symptoms and age vanishes for men, and even reverses for women. Thus, the association between age and mental health is mediated by the health and living conditions of older persons; age by itself has no explanatory power.
\end{abstract}

Keywords: Depressive symptoms · Older persons $\cdot$ SHARE $\cdot$ EURO-D · Negative binomial model

\section{Introduction}

"There is no health without mental health" (EC 2005: 4). Mental health is an indivisible part of health and mental problems, and can drastically reduce the quality of life of those effected and of their families. Good mental health is important for individuals as well as for society. At individual level, it enables people to achieve their intellectual and emotional potential and to find their roles in social and working life. At societal level, good mental health is important for social and economic welfare.

Mental disorders are common. Estimates for the adult population in the EU affected by some form of mental ill-health and mental disorder within the past 12 months range between $20 \%$ and $27 \%$ (EC 2004b; Wittchen/Jacobi 2005). In the 
near future, depression will become the disease group with the second heaviest toll globally (EC 2004a). Accordingly, there is an increasing interest in the mental health of the EU population, and a strong political commitment to action in this field.

The most important forms of mental disorder are depression, specific phobias, somatoform disorders and alcohol dependence (Wittchen/Jacobi 2005). Depression and dementia constitute the two most important mental problems in later life (Copeland et al. 1999b). Increasing life expectancy may contribute to a rise in prevalence among the aged. However, empirical evidence of the association between age and depressive symptoms is varied. Analyses of depression in later life (i.e. above age 65) reveal a strong positive association between the prevalence of symptoms of depression and age (Stordal et al. 2001; Castro-Costa et al. 2007), a modest association with age (Prince et al. 1999b), or a lack of an overall tendency towards depression rising with age (Trollor et al. 2007; Korten/Henderson 2000; Litwin 2002; Verropoulou/Tsimbos 2007), except among the oldest old (Copeland et al. 1999b). Controlling for mediating effects, Blazer et al. (1991) and Berkman et al. (1986) found an inverse association between age and depression. Mediating variables generally transmit the effect of an independent variable on a dependent variable (Baron/Kenny 1986; MacKinnon et al. 2007). The different results presented in the literature, ranging from negative to zero to positive effects, may be due to selective samples or caused by different modelling methods of the age-depression profile, in particular due to adjustments for different sets of covariates that have different influences on the age effect of depressive symptoms (Yang 2007).

In this paper, we analyse the association between age and depression, controlling for well-known determinants of mental health, using a representative sample of older persons in several European countries. In contradistinction to previous studies, we pay particular attention to the underlying statistical model and analyse systematically the change in the effect of age on depressive symptoms when controlling for these mediating variables. We also want to stress that the present study is not a psychiatric or gerontological contribution targeting physicians or psychiatrists, but addresses sociologists, demographers and the broad group of those who are interested in ageing.

\section{Literature review}

Mental health has two dimensions: positive mental health and negative mental health. The positive dimension refers to the concepts of well-being and ability to cope in the face of adversity. The negative dimension includes psychological distress and psychiatric disorders, and relates to the presence of symptoms. Positive and negative mental health cover different aspects. (EC 2004a).

There are several measures for analysing mental health. Some instruments measure more generic factors, such as psychological distress, by recording the presence or absence of certain symptoms such as anxiety or depression. This type of instrument produces a mental health score, and for some of them, cut-off points can be used to categorise people into groups such as "probable cases" with mental 
health disorders. ${ }^{1}$ Other instruments are designed to produce answers which correspond to diagnoses of mental disorders (e.g., mood disorder, anxiety disorders and drug and alcohol disorders) and generate estimates of the prevalence of particular disorders ${ }^{2}$ (EC 2004a).

There is a great wealth of literature on mental health, focussing inter alia on clinical aspects and treatments (e.g., Beck 1987; Beck 1991; Adam 1998; Drake et al. 2001; Amber et al. 2006), social and economic costs of mental health (e.g. Hamilton et al. 1997; Stephens/Joubert 2001; Whooley et al. 2002), health care services and their use (e.g., Alonso et al. 2004c, Harris et al. 2006) and the relation between mental and physical health (e.g., Braam et al. 2005; Opolski/Wilson 2005).

The determinants of mental condition are multiple, including biological (e.g., genetics, sex), individual (e.g. health, personal experiences), familial and social (e.g., family status, social support), economic and environmental conditions (e.g., social status and living arrangements). The following brief overview of the literature focuses on central variables associated with depression.

In general, a higher number of depressive symptoms is typically found among women (Prince et al. 1999b; Alonso et al. 2004a; Lehtinen et al. 2005; Carta et al. 2005; Barry et al. 2008; Hopcroft/Bradley 2007; Zunzunegui et al. 2007). Copeland et al. (1999a) assessed the prevalence of depression among individuals aged 65 and over in nine European centres, and found that also women outnumber men among older persons with signs of depression. Their meta analysis shows an overall prevalence of diagnostic depression of $12.3 \%$ ( $14.1 \%$ for women, and $8.6 \%$ for men).

Marital status is an important determinant of depressive symptoms: Widowed and divorced persons have poorer mental health (Dean et al. 1992; Lehtinen et al. 2003; Carta et al. 2005). Mental disorders are more common among persons who were either never married or who were previously married and currently have no partner (Alonso et al. 2004b; Buber/Engelhardt 2008; Schaan 2009). Having a trustbased relationship seems to have a protective effect.

Several studies identify links between the prevalence of mental disorders and socio-economic disadvantages. In general, relatively high frequencies of mental disorders are associated with a poor level of education, material disadvantage, low family income, unemployment and living on a pension (e.g. Beekman et al. 1999; Alonso et al. 2004b; Fryers et al. 2005; Lehtinen et al. 2005; Carta et al. 2005; Ladin 2008; Litwin/Sapir 2008). Consistent with analyses of European data, Kess/er et al. (1994) finds elevated rates of affective and anxiety disorders among women and individuals with lower socio-economic status for the US. Other studies show a statistically significant relationship between place of residence and mental health, with the lowest values being registered in large cities (Ayuso-Mateos et al. 2001; Lehtinen et al. 2003; Lehtinen et al. 2005).

1 Instruments in this category include Mental Health Index MHI-5, GHO (General Health Questionnaire) or EURO-D.

2 As an example we mention the CIDI (Composite International Diagnostic Interview) instrument. 
Poor physical health is one of the most important risk factors for depression in older adults. Physical health problems are demonstrated to be a predictor of both the onset and the persistence of depression (e.g. Berkman et al. 1986; Katz 1996; Geerlings et al. 2000; Lenze et al. 2001; Fiske et al. 2003; Braam et al. 2005; Jang et al. 2007). Moreover, cognitive health also turns out to be associated with mental health (e.g. Jorm 2000; Reischies/Neu 2000; Scogin/Rohling 1989). Berkman et al. (1986) show that the addition of functional disability to a multivariate model substantially weakens the association between age and depressive symptoms. Based on US data, Blazer et al. (1991) and Mirowsky and Ross (1992) show that the upward trend of depression in later life reverses after including as covariates mediating variables such as marital, employment, economic and sociodemographic status. More recently, Cairney and Krause (2005) show that depressive symptoms in later life are associated with age, gender, living arrangements and education. They suggest that key social factors are related to depressive symptoms in later life. Thus, the question arises as to whether there is a true causal link between age and depressive symptoms. We hypothesize that this relationship is mediated by special circumstances associated with the ageing process. The different and even contradictory findings on the age-depression profile in the literature may be due to different the consideration of different socio-demographic characteristics, health conditions and economic strains.

To answer this question, we take advantage of the multifaceted structure of the Survey of Health, Ageing and Retirement in Europe (SHARE), a representative European dataset that allows the comparison of health status in a variety of countries as well as the analysis of the determinants of health in a very broad context. SHARE includes representative samples of the total population of eleven European countries and Israel. It makes it possible to study symptoms of mental health of Europeans aged 50 and older.

In this paper, we analysed the association between age and depressive symptoms - measured by EURO-D score - of persons aged 50 to 89, adjusting for living arrangements, education, economic constraints, limitations in activities of daily living, cognitive orientation, functional impairments and chronic diseases in a representative sample in eleven European countries and Israel. The SHARE data permit us to take into consideration these various dimensions which might be responsible for an age-specific increase in symptoms of depression.

\section{Data, Variables And Method}

\subsection{Data}

The study is based on the first wave of the Survey of Health, Ageing and Retirement in Europe (SHARE), which includes detailed cross-national information on health, well-being, economic circumstances and social networks for twelve countries, namely Austria, Belgium, Denmark, France, Germany, Greece, Israel, Italy, the Netherlands, Sweden, Switzerland and Spain. The data of the first wave which we utilize 
were collected between 2004 and 2005. SHARE covers the non-institutionalised population aged 50 and older. "Release 2.0.1" of wave 1 comprises data on 31,115 individuals in 21,176 households, the weighted average response rate being $61.6 \%$ (Börsch-Supan/Jürges 2005; see also http://www.share-project.org).

The focus of the present study is on depressive symptoms of persons aged 50 to 89. Respondents aged 90 or older are excluded due to low numbers (285 persons aged 90 to 104). The current sample includes 28,538 persons $(13,068$ men and 15,470 women) with complete information on depressive symptoms, education and living arrangements. The mean age is 64 for men and 66 for women.

\subsection{Variables}

Our central variable is depressive mood measured by the number of depressive symptoms. Our study measures mental health on the EURO-D scale. This is an instrument which is symptom oriented, based on the presence or absence of depressive symptoms, but does not generate diagnoses of different mental disorders (e.g., mood disorder, anxiety disorders and drug and alcohol disorders). EURO-D was developed in an 11-country European collaboration to compare symptoms of depression in 14 European centres. Five depression measures ${ }^{3}$ are harmonised to form a 12-item scale (Prince et al. 1999a). The reliability of EURO-D has been reported to be good. In terms of its validity, it has been shown to correlate well with other wellknown health measures (Prince et al. 1999a). The EURO-D is an internally consistent scale, captures the essence of its parent instruments, has been validated in a cross-European study of depression prevalence, and facilitates a valid comparison of risk factor associations between centres (Prince et al. 1999a). The 12 contributing items for the EURO-D scale are: depression, pessimism, suicidality (wishing death), guilt, sleep, interest, irritability, appetite, fatigue, concentration, enjoyment, tearfulness. The time frame of the symptoms refers mostly to the month preceding the interview. The EURO-D is a discrete measure of depressive symptoms; the core ranges from 0 to 12, with higher scores indicating higher levels of depression. Dewey and Prince (2005) suggest to set a threshold at a score of 3 and define clinically significant depression as a EURO-D score greater than 3 . In the current sample, EURO-D was internally consistent for all countries, with Cronbach alpha being 0.74 for the current pooled sample, ranging from 0.62 (in Switzerland) to 0.78 (in Spain). Thus, EURO-D is a feasible instrument for evaluating different dimensions of mental health. However, we are not able to distinguish between mild and severe mental disorders.

To allow for a flexible, non-parametric association between age and the number of depressive symptoms, 5-year age groups are included in the regressions. Based on the literature, we include in the analyses socio-demographic characteristics and

3 Geriatric Mental State-AGECAT (GMS-AGECAT), SHORT-CARE, Centre for Epidemiological Studies Depression scale (CES-D), Zung Self-Rating Depression Scale (ZSDS), Comprehensive Psychopathological Rating Scale (CPRS). 
health conditions that were found to have an effect on mental health. The current study includes the following covariates:

(a) living arrangements: alone; as a couple; alone with other persons; as a couple with other persons,

(b) highest level of education: primary school (ISCED 0-1); lower secondary (ISCED 2); higher secondary (ISCED 3-4); tertiary education (ISCED 5-6),

(c) cognitive orientation based on the orientation to date, month, year and day of week; ranging from 0 (bad orientation) to 4 (good orientation),

(d) limitations in the following activities of daily living (ADL): dressing; walking across a room; bathing or showering; eating; getting in and out of bed; using the toilet,

(e) chronic diseases: no chronic diseases; mild chronic diseases (i.e. high blood pressure, high blood cholesterol, diabetes, asthma, osteoporosis, stomach, duodenal or peptic ulcer, cataracts or hip fracture), and severe chronic diseases (i.e. heart attack or chronic lung disease) (Ka/wij/Vermeulen 2008), and

(f) economic strain: subjective indicator of financial distress, based on the question of how respondents make ends meet: with great difficulty; with some difficulty; fairly easily; easily.

The distribution of these variables for the pooled sample is listed in Tables 2a and $2 \mathrm{~b}$ below. With increasing age, the number of respondents goes down both for men and women. The vast majority of men and women live with a spouse or partner; while about one-third of women live alone, only $17 \%$ of men do so. Differentiating by the highest educational level attained, it turns out that $56 \%$ of all men and $42 \%$ of women have completed higher secondary or tertiary education. Women report economic constraints more frequently than men (34\% of women and $28 \%$ of men). When it comes to health, about $10 \%$ of respondents report one or more limitations in their ADL; $15 \%$ have a less than good cognitive orientation, and about $25 \%$ of men and $21 \%$ of women suffer from severe chronic diseases.

\subsection{Statistical procedure}

In a first step, the association between age and depressive symptoms is analysed by comparing means of EURO-D by age as well as by confidence intervals. To complement the first descriptive results, t-tests are used to estimate mean differences in EURO-D scores between men and women, with $95 \%$ confidence intervals. Next, multivariate regression models are applied to analyse the association between age and depressive symptoms, controlling for socio-demographic indicators (living arrangements, education and economic constraints), as well as diverse dimensions of health (cognitive orientation, limitations in activities of daily living, chronic diseases). To account for country-specific heterogeneity, we include country dummies in all models. Covariates are included stepwise so as to detect possible changes in the magnitude as well as in the direction of associations between age and depressive symptoms. As a general rule, the reference category is the largest group in each covariate. For the variable highest level of education, the largest group contains 
persons with a basic level of education. Since all respondents in Denmark have at least lower secondary education, "basic education" cannot be the reference group in this country. In order to have the same reference group in all countries, "higher secondary or tertiary education", i.e. the highest educational level, is chosen as the reference group. Analyses are carried out separately for men and women to allow for a different shape of the association between age and the number of depressive symptoms, for a different constant in the estimated model, and for a different association between the explanatory variable and the covariates included in the model.

The explanatory variable of the current study is the number of depressive symptoms, a discrete variable ranging from 0 to 12. It can be classified as a count variable indicating how many depressive symptoms a respondent reported. In principle, we were able to analyse these data using standard multiple linear regression. However, the preponderance of zeros ( $n=6,760$; i.e. $24 \%$ ) and the small values indicate that the dependent variable is clearly discrete. The Poisson regression model accounts for these characteristics and is used widely to study such data. A common problem with the standard Poisson model is that the equidispersion assumption $(E(Y \mid X)=$ $\mathrm{V}(\mathrm{Y} \mid \mathrm{X})=\lambda)$ is violated, i.e. the conditional mean does not equal the conditional variance. To solve this problem, different approaches are proposed, including the generalised event count model, the generalised Poisson model and the negative binomial model to account for overdispersion $(\mathrm{E}(\mathrm{Y} \mid \mathrm{X})<\mathrm{V}(\mathrm{Y} \mid \mathrm{X}))$ and underdispersion $(E(Y \mid X)>V(Y \mid X)$ ), with $X$ and $Y$ being random variables (Winkelmann 2003). $A$ statistical test for dispersion reveals strong and significant evidence of overdispersion, i.e. the conditional variance exceeds the conditional mean in the full sample. Therefore, we estimate a negative binomial model which accounts for overdispersion and for the prevalence of zero counts in the data (Winkelmann 2003).

In this model, the probability $\operatorname{Pr}(y \mid x)$ of observing any observed count $y$ is given by

$$
\operatorname{Pr}(Y=y \mid X=x)=\operatorname{Pr}(y \mid x)=\frac{\Gamma\left(y+\alpha^{-1}\right)}{y ! \Gamma\left(\alpha^{-1}\right)}\left(\frac{\alpha^{-1}}{\alpha^{-1}+\mu}\right)^{\alpha^{-1}}\left(\frac{\mu}{\alpha^{-1}+\mu}\right)^{y}
$$

where $X$ and $Y$ are random variables, $x$ is the vector of observed characteristics, $\Gamma$ (') is the gamma function and $\alpha$ and $\mu$ are parameters to be estimated empirically. The parameter $\alpha$ reflects unobserved heterogeneity and determines the degree of dispersion in the predictions. Systematic variation can be introduced in the parameter $\mu$ as in a log-linear model: $\mu=\exp \left(x^{\prime} \beta\right)$. The coefficients in this model cannot be interpreted directly; only the sign of a coefficient indicates the direction of an effect. We refer to Long and Freese (2006) and Winkelmann (2003) for further mathematical details.

To visualise the fit of the current count model with a negative binomial regression model, the observed relative frequencies, both the variable (number of depressive symptoms) and the predicted probabilities are plotted for each value of the count. Figure 1 clearly shows that the negative binomial distribution fits the data well and is an appropriate tool for the current study. 
Fig. 1: Observed relative frequencies and predicted probabilities for the number of depressive symptoms

Relative frequency and probalbility

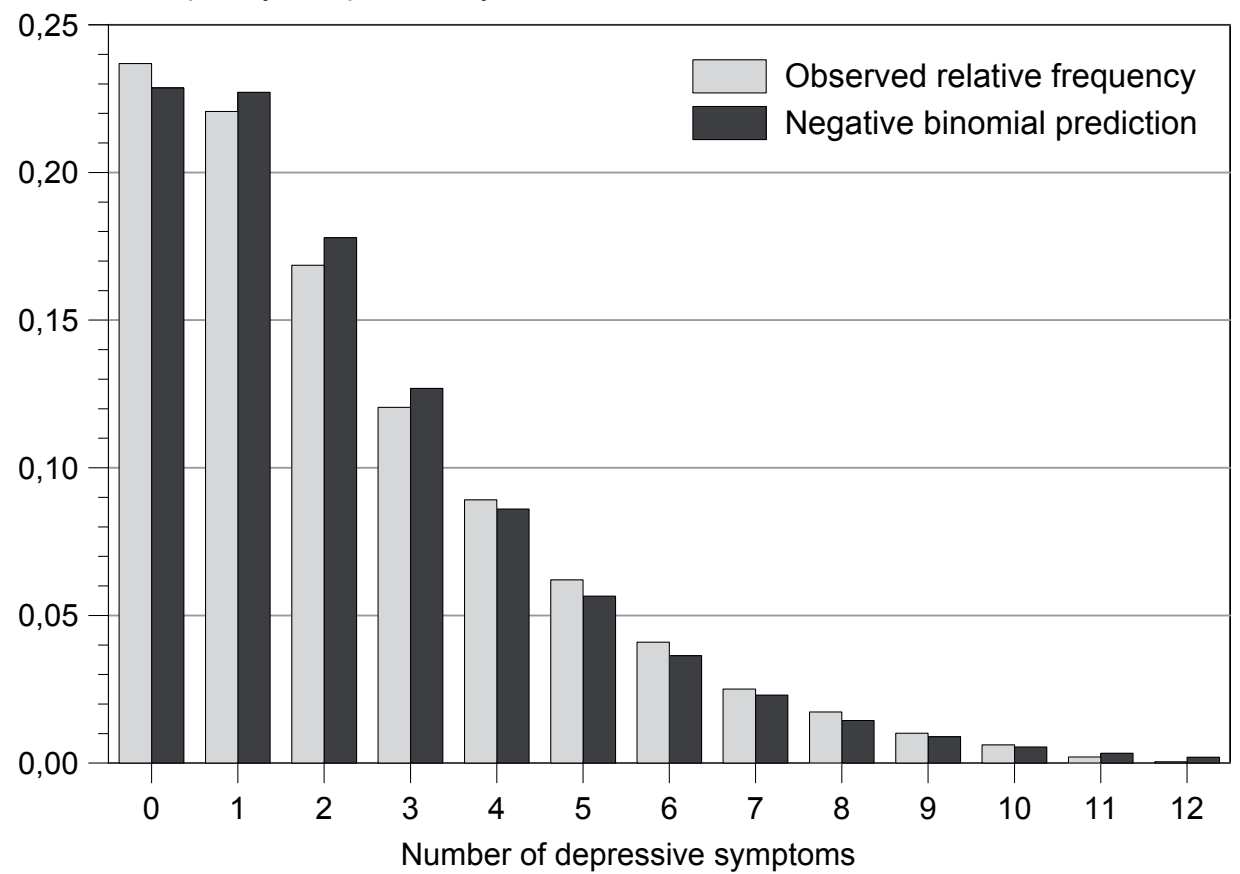

Source: SHARE 2004-05, Release 2.0.1

\section{$4 \quad$ Results}

At first sight, the prevalence of depressive symptoms appears to increase with age among men and women, with women reporting more depressive symptoms compared to men. Figure 2 depicts the mean EURO-D scores for men and women. Roughly speaking, the mean EURO-D score increases between ages 50 to 89 from 1.6 to 3.0 among men and from 2.5 to 3.8 among women. Confidence intervals become broader at older ages, indicating a considerable variation in the number of depressive symptoms at older ages.

Table 1 includes the mean number of depressive symptoms among men and women within 5 -year age groups and $t$ tests estimating mean differences in EUROD scores between men and women, as well as confidence intervals indicating the difference. The results show that women reported significantly more depressive symptoms than men, and, moreover, the gender gap widens with rising age (50-54: difference of 0.85 symptoms; $80-84$ : difference of 1.05 symptoms). It is therefore appropriate to run the analyses separately for men and women to allow for a different shape of the association between age and the number of depressive symptoms, 
Fig. 2: $\quad$ Mean number of depressive symptoms by age and gender

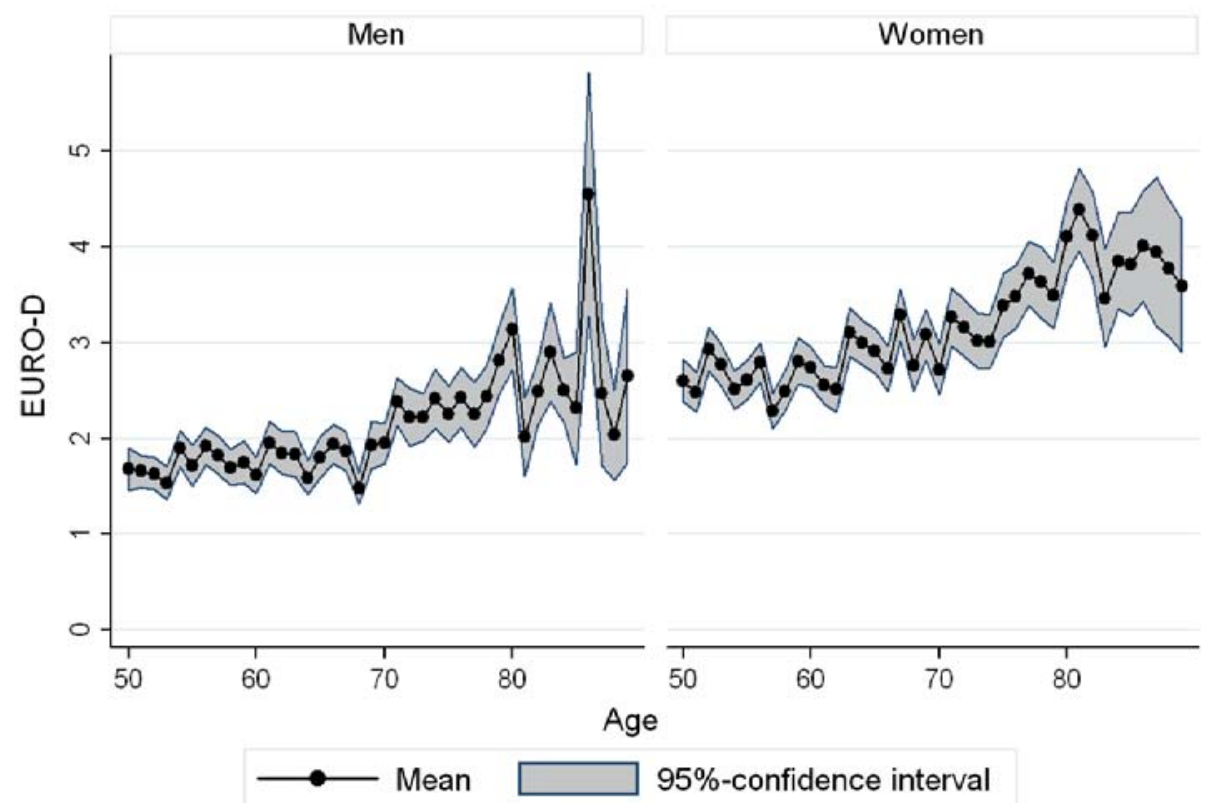

Source: SHARE 2004-05, Release 2.0.1

Tab. 1: Mean number of depressive symptoms by age groups and gender

\begin{tabular}{lccc}
\hline & Men & Women & Mean difference $(95 \%$-Confidence Interval) \\
\hline $50-54$ & 1.72 & 2.57 & $-0.85(-0.97 ;-0.74)$ \\
$55-59$ & 1.70 & 2.47 & $-0.77(-0.88 ;-0.66)$ \\
$60-64$ & 1.63 & 2.56 & $-0.92(-1.04 ;-0.81)$ \\
$65-69$ & 1.77 & 2.66 & $-0.89(-1.02 ;-0.77)$ \\
$70-74$ & 1.94 & 2.84 & $-0.90(-1.05 ;-0.75)$ \\
$75-79$ & 2.29 & 3.25 & $-0.97(-1.16 ;-0.76)$ \\
$80-84$ & 2.46 & 3.50 & $-1.05(-1.29 ;-0.81)$ \\
$85-89$ & 2.63 & 3.46 & $-0.82(-1.23 ;-0.42)$ \\
\hline
\end{tabular}

Source: SHARE 2004-05, Release 2.0.1

for a different constant in the estimated model, and for a different association between the explanatory variable and the covariates included in the model.

For the multivariate analysis, we apply negative binomial regression models as described in the previous section. Tables $2 a$ and $2 b$ give the estimated non-exponentiated coefficients of the various variables separately for males and females, with the respective reference group having a value of zero. Positive coefficients imply an increase in the number of depressive symptoms; negative coefficients stand for a 
Tab. 2a: Coefficients of a negative binomial regression model for the associations between EURO-D scores and age, living arrangements, education, ADL limitations, cognitive orientation, health and economic strain, male respondents

\begin{tabular}{|c|c|c|c|c|c|c|c|c|}
\hline & Model 1 & Model A & Model B & Model C & Model D & Model E & Model F & $\begin{array}{c}\text { Distrib. in } \\
\%\end{array}$ \\
\hline \multicolumn{9}{|l|}{ Age } \\
\hline $50-54^{a}$ & 0 & 0 & 0 & 0 & 0 & 0 & 0 & 20 \\
\hline $55-59$ & 0.01 & 0.03 & -0.00 & 0.01 & 0.00 & 0.01 & -0.04 & 19 \\
\hline $60-64$ & -0.00 & 0.02 & -0.03 & 0.01 & -0.02 & -0.01 & $-0.11 *$ & 17 \\
\hline $65-69$ & 0.07 & $0.11^{*}$ & 0.03 & $0.08+$ & 0.05 & 0.05 & -0.06 & 16 \\
\hline $70-74$ & $0.19 * * *$ & $0.22 * * *$ & $0.13^{*}$ & $0.20 * * *$ & $0.14^{* *}$ & $0.16^{* *}$ & 0.03 & 12 \\
\hline $75-79$ & $0.30 * * *$ & $0.32 * * *$ & $0.23^{* * *}$ & $0.34 * * *$ & $0.20 * * *$ & $0.25^{* * *}$ & $0.10+$ & 9 \\
\hline $80-84$ & $0.41 * * *$ & $0.43^{* * *}$ & $0.34 * * *$ & $0.43^{* * *}$ & $0.21 * *$ & $0.35^{* * *}$ & $0.19^{* *}$ & 5 \\
\hline $85-89$ & $0.53^{* * *}$ & $0.50 * * *$ & $0.44 * * *$ & $0.55^{* * *}$ & $0.30^{* *}$ & $0.43^{* * *}$ & $0.34^{* *}$ & 2 \\
\hline \multicolumn{9}{|l|}{ Living arrangements } \\
\hline Couple $^{a}$ & & 0 & & & & & & 52 \\
\hline Ego alone & & $0.22^{* * *}$ & & & & & & 17 \\
\hline Couple with others & & $0.08 *$ & & & & & & 28 \\
\hline Ego with others & & $0.34 * * *$ & & & & & & 3 \\
\hline \multicolumn{9}{|l|}{ Highest level of education } \\
\hline Primary school & & & $0.27 * * *$ & & & & & 29 \\
\hline Lower secondary & & & $0.11 *$ & & & & & 15 \\
\hline Higher secondary or tertiary ${ }^{a}$ & & & 0 & & & & & 56 \\
\hline \multicolumn{9}{|l|}{ Make ends meet } \\
\hline With great difficulty & & & & $0.77^{* * *}$ & & & & 8 \\
\hline With some difficulty & & & & $0.40 * * *$ & & & & 20 \\
\hline Fairly easily & & & & $0.14^{* *}$ & & & & 27 \\
\hline Easily $^{a}$ & & & & 0 & & & & 19 \\
\hline Missing answer & & & & $0.21 * * *$ & & & & 26 \\
\hline \multicolumn{9}{|l|}{ ADL limitations } \\
\hline None ${ }^{a}$ & & & & & 0 & & & 91 \\
\hline 1 and more limitations & & & & & $0.77^{* * *}$ & & & 9 \\
\hline \multicolumn{9}{|l|}{ Cognitive orientation } \\
\hline 0 (bad orientation) to 3 & & & & & & $0.33^{* * *}$ & & 15 \\
\hline $4\left(\right.$ good orientation) ${ }^{a}$ & & & & & & 0 & & 85 \\
\hline \multicolumn{9}{|l|}{ Chronic diseases } \\
\hline No & & & & & & & $-0.31 * * *$ & 34 \\
\hline Mild $^{\mathrm{a}}$ & & & & & & & 0 & 41 \\
\hline Severe & & & & & & & $0.30 * * *$ & 25 \\
\hline Constant & $0.49 * * *$ & $0.40 * * *$ & $0.43^{* * *}$ & $0.24 * * *$ & $0.44 * * *$ & $0.78^{* * *}$ & $0.60 * * *$ & \\
\hline MacFadden's $\mathrm{R}^{2}$ & 0.012 & 0.014 & 0.014 & 0.022 & 0.027 & 0.015 & 0.024 & \\
\hline $\mathrm{N}$ & 13,017 & 13,017 & 13,017 & 13,017 & 13,015 & 13,010 & 13,017 & \\
\hline
\end{tabular}

Notes: All models additionally include country dummies. The number of $\mathrm{N}$ differs in the various models due to missing data.

a Reference category. $+p<0.10 ;{ }^{*} p<0.05 ;{ }^{*} p<0.01 ;{ }^{* *} p<0.001$.

Source: SHARE 2004-05, Release 2.0.1; own calculations

decrease. All models include additionally country dummies to account for country heterogeneity in the number of depressive symptoms (results not reported here).

The association between age and number of depressive symptoms is approximated with a piecewise constant function for 5 -year age groups. This modeling procedure allows a flexible form and does not imply a specific association between the 
Tab. 2b: Coefficients of a negative binomial regression model for the associations between EURO-D scores and age, living arrangements, education, ADL limitations, cognitive orientation, health and economic strain, female respondents

\begin{tabular}{|c|c|c|c|c|c|c|c|c|}
\hline & Model 1 & Model A & Model B & Model C & Model D & Model E & Model F & $\begin{array}{c}\text { Distrib. in } \\
\%\end{array}$ \\
\hline \multicolumn{9}{|l|}{ Age } \\
\hline $50-54^{a}$ & 0 & 0 & 0 & 0 & 0 & 0 & 0 & 18 \\
\hline $55-59$ & -0.04 & -0.03 & $-0.06+$ & -0.04 & -0.05 & -0.04 & $-0.11 * *$ & 16 \\
\hline $60-64$ & 0.00 & 0.01 & -0.04 & -0.00 & -0.03 & -0.01 & $-0.09 * *$ & 15 \\
\hline $65-69$ & $0.06+$ & 0.05 & 0.00 & 0.05 & 0.03 & 0.05 & $-0.07+$ & 15 \\
\hline $70-74$ & $0.08^{*}$ & $0.07+$ & -0.00 & $0.06+$ & 0.01 & 0.06 & $-0.06+$ & 13 \\
\hline $75-79$ & $0.24 * * *$ & $0.20^{* * *}$ & $0.14 * * *$ & $0.24 * * *$ & $0.15^{* * *}$ & $0.19 * * *$ & 0.06 & 11 \\
\hline $80-84$ & $0.34 * * *$ & $0.28^{* * *}$ & $0.23^{* * *}$ & $0.33^{* * *}$ & $0.18^{* * *}$ & $0.25 * * *$ & $0.15^{* *}$ & 9 \\
\hline $85-89$ & $0.30 * * *$ & $0.22^{* * *}$ & $0.19 * * *$ & $0.30 * * *$ & 0.04 & $0.19 * * *$ & $0.14^{*}$ & 3 \\
\hline \multicolumn{9}{|l|}{ Living arrangements } \\
\hline Couple $^{a}$ & & 0 & & & & & & 40 \\
\hline Ego alone & & $0.14^{* * *}$ & & & & & & 33 \\
\hline Couple with others & & 0.04 & & & & & & 17 \\
\hline Ego with others & & $0.18^{* * *}$ & & & & & & 10 \\
\hline \multicolumn{9}{|l|}{ Highest level of education } \\
\hline Primary school & & & $0.28 * * *$ & & & & & 37 \\
\hline Lower secondary & & & $0.20^{* * *}$ & & & & & 21 \\
\hline Higher secondary or tertiary ${ }^{a}$ & & & 0 & & & & & 42 \\
\hline \multicolumn{9}{|l|}{ Make ends meet } \\
\hline With great difficulty & & & & $0.55^{* * *}$ & & & & 11 \\
\hline With some difficulty & & & & $0.35^{* * *}$ & & & & 23 \\
\hline Fairly easily & & & & $0.12 * * *$ & & & & 25 \\
\hline Easily $^{a}$ & & & & 0 & & & & 14 \\
\hline Missing answer & & & & $0.17 * * *$ & & & & 27 \\
\hline \multicolumn{9}{|l|}{ ADL limitations } \\
\hline None ${ }^{a}$ & & & & & 0 & & & 89 \\
\hline 1 and more limitations & & & & & $0.54 * * *$ & & & 11 \\
\hline \multicolumn{9}{|l|}{ Cognitive orientation } \\
\hline 0 (bad orientation) to 3 & & & & & & $0.31 * * *$ & & 15 \\
\hline $4(\text { good orientation) })^{a}$ & & & & & & 0 & & 85 \\
\hline \multicolumn{9}{|l|}{ Chronic diseases } \\
\hline No & & & & & & & $-0.33^{* * *}$ & 29 \\
\hline Mild $^{a}$ & & & & & & & 0 & 50 \\
\hline Severe & & & & & & & $0.30 * * *$ & 21 \\
\hline Constant & $0.92^{* * *}$ & $0.86^{* * *}$ & $0.83^{* * *}$ & $0.71 * * *$ & $0.89 * * *$ & $1.20 * * *$ & $1.05^{* * *}$ & \\
\hline MacFadden's $\mathrm{R}^{2}$ & 0.016 & 0.017 & 0.019 & 0.024 & 0.027 & 0.020 & 0.027 & \\
\hline $\mathrm{N}$ & 15,399 & 15,399 & 15,399 & 15,399 & 15,396 & 15,389 & 15,399 & \\
\hline
\end{tabular}

Notes: All models additionally include country dummies. The number of $\mathrm{N}$ differs in the various models due to missing data.

a Reference category. $+p<0.10 ;{ }^{*} p<0.05 ;{ }^{*} p<0.01 ;{ }^{* *} p<0.001$.

Source: SHARE 2004-05, Release 2.0.1, own calculations

number of depressive symptoms and age. This would be the case if, for example, age was entered for a linear relationship or age and age squared for a quadratic one. The sole association between age and depressive symptoms is confirmed by the estimated significant coefficients for ages 70 and above (Tab. 2a and 2b, Model 1). 
Thus, whilst controlling for country-specific heterogeneity, our results reveal in a first step slightly higher levels for men and women aged 65-69, and significantly higher levels of depressive symptoms in the age groups 70-74, 75-79, 80-84 and $85-89$, compared to the reference group of respondents aged $50-54$. The increase with age is more pronounced among men compared to women.

In a next step, variables that are found to be correlated with depressive symptoms are included separately in the models to analyze the change in size of the age coefficients, whilst controlling for these characteristics. Models A, B and C in Tables $2 \mathrm{a}$ and $2 \mathrm{~b}$ include living arrangements, education, and economic constraints as covariates separately, while Models $D, E$ and $F$ take health conditions into consideration.

First of all, all covariates are significantly associated with the number of depressive symptoms with the expected signs both for men and women. Living alone as well as living with people other than a partner, low levels of educational attainment, increased economic strains, ADL limitations, less than good cognitive orientation and severe chronic diseases are associated with an increased number of depressive symptoms.

The best model fit is measured by McFadden's $R^{2}$ results for financial constraints, chronic diseases and ADL limitations for both genders. For women, whilst controlling for each single covariate, the age effects diminish, with the exception of economic constraints. A significantly increased number of depressive symptoms can only be observed for age 75 and older (Models $A$ to $E$ ) and age 80 and older in Model F. For males, we observe only reduced age effects, whilst controlling for health conditions (ADL limitations, cognitive orientation, and chronic diseases). Living arrangements, level of education and economic strain do not alter the age effects in the way we observe for females.

Most interestingly, though, the estimated constant effect increases remarkably both for males and females in Models $E$ and $F$, where cognitive impairment and chronic diseases are controlled for. Thus, the average number of depressive symptoms increases, while the effects for the different age groups decline compared to Model 1. Moreover, controlling for chronic diseases, only men aged 75 and older and women aged 80 and older have significantly increased numbers of depressive symptoms.

The coefficients for age change significantly with the stepwise inclusion of different covariates. First, the initial strong positive association between age and the number of depressive symptoms weakens if one includes socio-demographic characteristics (Tab. 3, Model 2). Second, including as covariates diverse dimensions of health virtually eliminates the age-depressive symptoms association among men, and even reverses the association among women. While men and women aged 70 and above initially have significantly higher levels of depressive symptoms compared to those in their early fifties, in the model including health indicators (Model 3) the estimated coefficients in the male sample are small and no longer significant (for age 70 and above). For females, all estimated coefficients turn negative and are even significant for ages 55 to 74 and 85 to 89 , the corresponding levels being between -0.09 and -0.13 . The final model includes socio-economic determinants as 
Tab. 3: Coefficients of a negative binomial regression model for the associations between EURO-D scores and age, living arrangements, education, ADL limitations, cognitive orientation, health and economic strain

\begin{tabular}{|c|c|c|c|c|c|c|}
\hline & \multicolumn{3}{|c|}{ Men } & \multicolumn{3}{|c|}{ Women } \\
\hline & Model 2 & Model 3 & Model 4 & Model 2 & Model 3 & Model 4 \\
\hline \multicolumn{7}{|l|}{ Age } \\
\hline $50-54^{a}$ & 0 & 0 & 0 & 0 & 0 & 0 \\
\hline $55-59$ & 0.02 & -0.04 & -0.03 & $-0.05+$ & $-0.11 * * *$ & $-0.12^{* * *}$ \\
\hline $60-64$ & 0.00 & $-0.10^{*}$ & $-0.09+$ & -0.03 & $-0.11 * * *$ & $-0.13^{* * *}$ \\
\hline $65-69$ & 0.08 & -0.07 & -0.05 & -0.00 & $-0.09 * *$ & $-0.14^{* * *}$ \\
\hline $70-74$ & $0.18 * * *$ & 0.00 & 0.02 & -0.02 & $-0.12 * * *$ & $-0.19 * * *$ \\
\hline $75-79$ & $0.31 * * *$ & 0.03 & 0.06 & $0.14^{* * *}$ & -0.03 & $-0.09^{*}$ \\
\hline $80-84$ & $0.40 * * *$ & 0.03 & 0.06 & $0.21 * * *$ & -0.03 & $-0.11^{*}$ \\
\hline $85-89$ & $0.47^{* * *}$ & 0.12 & 0.11 & $0.16^{* *}$ & $-0.13^{* *}$ & $-0.22^{* * *}$ \\
\hline \multicolumn{7}{|l|}{ Living arrangements } \\
\hline Couple ${ }^{a}$ & 0 & & 0 & 0 & & 0 \\
\hline Ego alone & $0.16 * * *$ & & $0.16 * * *$ & $0.11 * * *$ & & $0.11 * * *$ \\
\hline Couple with others & 0.04 & & 0.04 & 0.03 & & 0.02 \\
\hline Ego with others & $0.28 * * *$ & & $0.28 * * *$ & $0.10^{* *}$ & & $0.07^{*}$ \\
\hline \multicolumn{7}{|l|}{ Highest level of education } \\
\hline Primary school & $0.15^{* * *}$ & & $0.09 * *$ & $0.22 * * *$ & & $0.17 * * *$ \\
\hline Lower secondary & 0.05 & & 0.02 & $0.16^{* * *}$ & & $0.13^{* * *}$ \\
\hline Higher secondary or tertiary ${ }^{a}$ & 0 & & 0 & 0 & & 0 \\
\hline \multicolumn{7}{|l|}{ Make ends meet } \\
\hline With great difficulty & $0.71 * * *$ & & $0.60 * * *$ & $0.48 * * *$ & & $0.40 * * *$ \\
\hline With some difficulty & $0.37 * * *$ & & $0.33^{* * *}$ & $0.30 * * *$ & & $0.26 * * *$ \\
\hline Fairly easily & $0.13^{* *}$ & & $0.13^{* *}$ & $0.10 * *$ & & $0.10^{* *}$ \\
\hline Easily ${ }^{a}$ & 0 & & 0 & 0 & & 0 \\
\hline Missing answer & $0.22 * * *$ & & $0.17 * * *$ & $0.17 * * *$ & & $0.15^{* * *}$ \\
\hline \multicolumn{7}{|l|}{ ADL limitations } \\
\hline None ${ }^{a}$ & & 0 & 0 & & 0 & 0 \\
\hline 1 and more limitations & & $0.63^{* * *}$ & $0.57 * * *$ & & $0.45^{* * *}$ & $0.41 * * *$ \\
\hline \multicolumn{7}{|l|}{ Cognitive impairment } \\
\hline 0 (bad orientation) to 3 & & $0.24 * * *$ & $0.21 * * *$ & & $0.23 * * *$ & $0.20 * * *$ \\
\hline 4 (good orientation) ${ }^{\mathrm{a}}$ & & 0 & 0 & & 0 & 0 \\
\hline \multicolumn{7}{|l|}{ Chronic diseases } \\
\hline No & & $-0.28 * * *$ & $-0.27^{* * *}$ & & $-0.30 * * *$ & $-0.28 * * *$ \\
\hline Mild $^{a}$ & & 0 & 0 & & 0 & 0 \\
\hline Severe & & $0.20^{* * *}$ & $0.25^{* * *}$ & & $0.19 * * *$ & $0.18^{* * *}$ \\
\hline Constant & $0.16^{* * *}$ & $0.53 * * *$ & $0.25 * * *$ & $0.62 * * *$ & $1.00 * * *$ & $0.75^{* * *}$ \\
\hline MacFadden's R² & 0.025 & 0.037 & 0.047 & 0.027 & 0.039 & 0.047 \\
\hline $\mathrm{N}$ & 13,017 & 13,008 & 13,008 & 15,399 & 15,386 & 15,386 \\
\hline
\end{tabular}

Notes: All models additionally include country dummies. The number of $\mathrm{N}$ differs in the various models due to missing data.

a Reference category. $+p<0.10 ;{ }^{*} p<0.05 ;{ }^{*} p<0.01 ;{ }^{* *} p<0.001$.

Source: SHARE 2004-05, Release 2.0.1; own calculations 
well as health indicators (Model 4). Whereas no age effect is observed for men, the estimated coefficients for women are all negative and significantly different from zero, indicating a lower number of depressive symptoms for ages 55 to $89 \mathrm{com}$ pared to women in their early fifties.

Figures $3 \mathrm{a}$ and $3 \mathrm{~b}$ depict the association between age and depressive symptoms for the stepwise setup of models. Figures $3 a$ and $3 b$ provide unambiguous evidence of the importance of socio-demographic characteristics and indicators of physical and cognitive health for depressive symptoms for both men and women, especially in advanced age. The piecewise constant functions representing the final multivariate model reveal that the increase in depression with age initially observed almost disappears for men, and even reverses for women. Our results indicate that socio-demographic characteristics and physical as well as cognitive health absorbe, and even go so far as to reverse, the association between age and EURO-D scores among older persons. Moreover, the separate analysis of men and women reveals gender-specific differences in the association between age and living arrangements on the one hand and EURO-D scores on the other. The association between educa-

Fig. 3a: Estimated association between age and the level of depression with and without covariates for socio-demographic and health characteristics, men

Coefficients of regression models

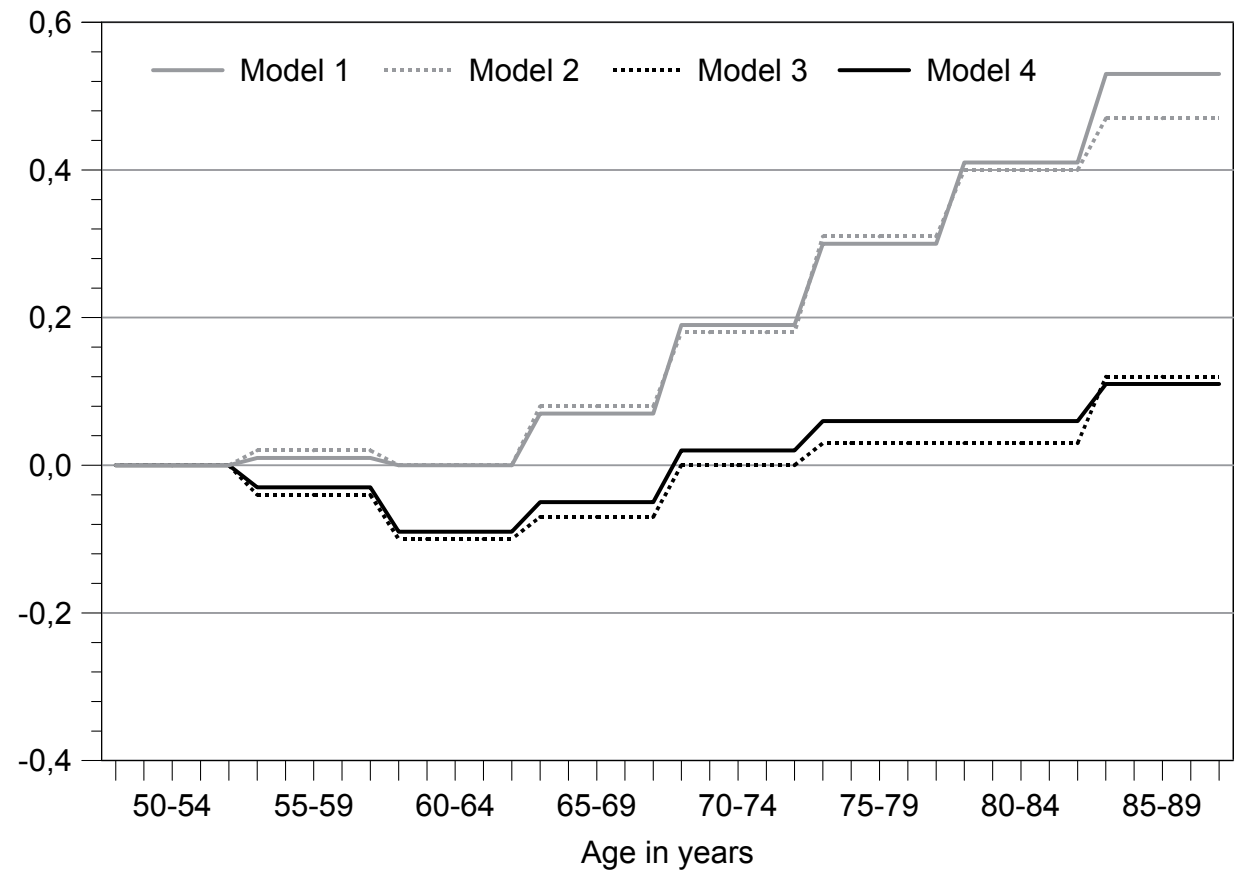

Note: The models refer to Tables $2 \mathrm{a}$ and 3.

Source: SHARE 2004-05, Release 2.0.1 
Fig. 3b: Estimated association between age and the level of depression with and without covariates for socio-demographic and health characteristics, women

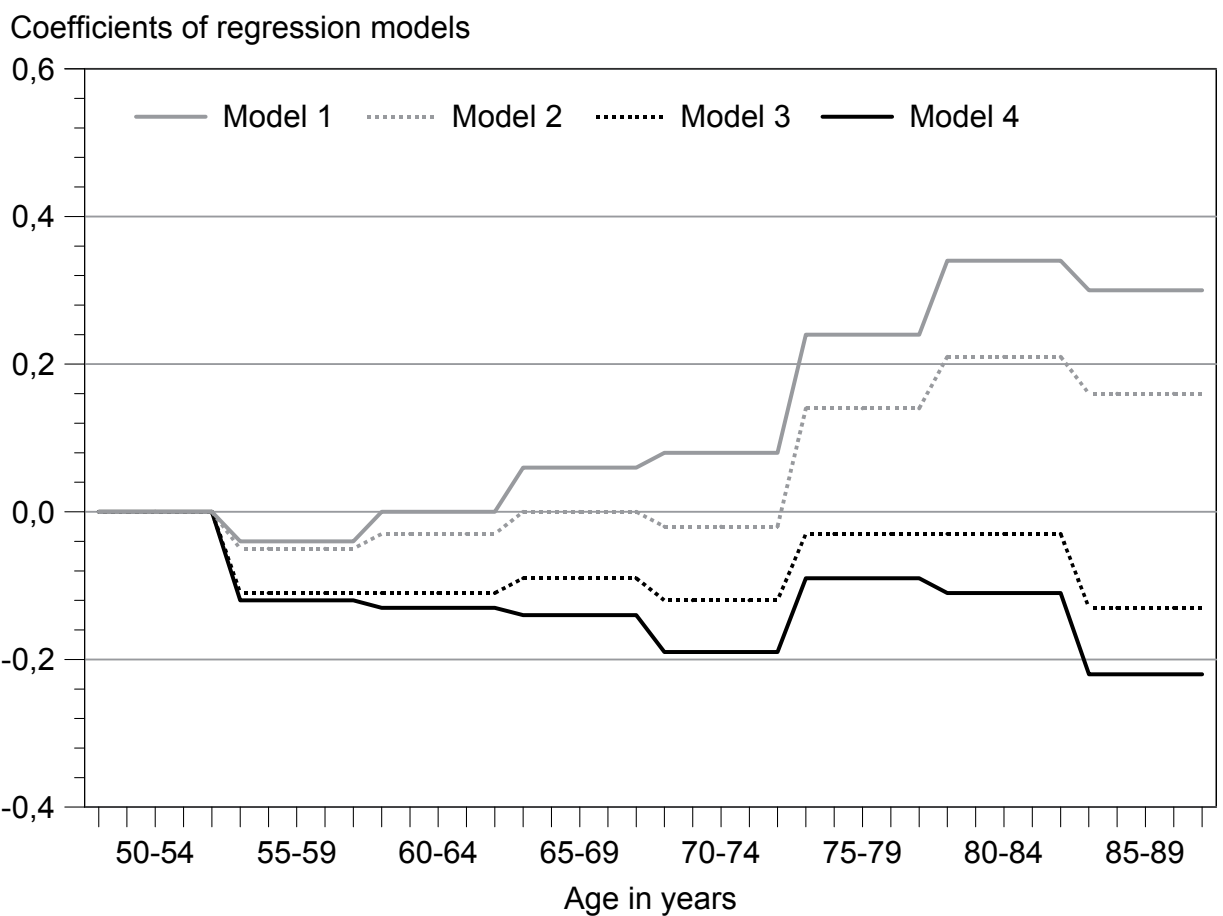

Note: The models refer to Tables $2 \mathrm{~b}$ and 3 .

Source: SHARE 2004-05, Release 2.0.1

tion and depressive symptoms is stronger among women, whereas the estimated coefficients for economic constraints, ADL limitations and chronic diseases are higher among men.

To test whether health, demographic characteristics and economic circumstances are mediating variables as they carry the influence of our independent variable (age) on our dependent variable (mental health), we apply a Sobel-Goodman mediation test. We find that the mediation effect of ADL limitations is highly significant, with approximately $49 \%$ of the total effect (of age on depressive mood) being mediated. In other words, age influences physical health, which in turn influences mental health. Gender-specific analysis reveals a more pronounced mediating effect among women than among men (52\% versus $42 \%$ ). Also, educational status can be regarded as a significant mediator, with $40 \%$ of the total effect being mediated. Cognitive impairment and chronic diseases, but also living arrangements and economic constraints, turn out to carry to a lesser degree the influence of age on mental health. 


\section{Discussion}

In this study we analyze the association between the prevalence of depressive symptoms and age, including as covariates socio-economic characteristics and health. In contrast to existing studies which provide mixed empirical evidence, SHARE allows the analysis of depressive symptoms of persons living in private households in various European countries based on a representative sample and a standardised questionnaire. In order to assess depressive symptoms, we use the EURO-D scale and estimate the effects of age, whilst controlling for well-known determinants of mental health using a negative binomial regression model as an innovative tool in analysing the number of depressive symptoms.

The present study reveals at first sight a significant increase in the number of depressive symptoms with age among both sexes. After including socio-economic characteristics and health conditions, the association almost disappears for men and even reverses for women. Living arrangements, educational level, financial strains, limitations in activities of daily living, chronic diseases and cognitive orientation are major determinants of depressive symptoms among older persons. Depressive symptoms are highly correlated with circumstances that are associated with old age, such as health problems, financial strains or the loss of one's partner. Once we had included these socio-demographic characteristics and health as covariates, age itself no longer had any explanatory power for men, and turns out to be positively correlated with depressive symptoms among women.

Our findings for European data are in line with findings for the US by Berkman et al. (1986), Blazer et al. (1991), Mirowsky and Ross (1992) and Cairney and Krause (2005). In addition, gender-specific analyses reveal that the association between the number of depressive symptoms and age reverses for women, whereas it "only" vanishes for men.

In a recent study based on the Greek SHARE data, Verropoulou and Tsimbos (2007:178) state that the positive association between age and depressive symptoms may be "spurious and mainly due to the older suffering from disabilities and stressful life events such as bereavement". Our evidence supports this hypothesis and additionally even reveals for women an inverse association with age, sociodemographic, economic and health indicators being included as covariates.

The outcomes of the covariates are in line with previous research (e.g. Dean et al. 1992), but they also reveal remarkable gender differences related to education and living arrangements and ADL limitation. For example, the impact of education is more marked among women than among men. Additional analyses for men and women not shown here reveal that divorce and widowhood have a different impact on the mental health of persons aged 50 and older. For men, it is widowhood that had a stronger negative impact on mental health, while for women it is divorce (see also Buber/Engelhardt 2008).

The stepwise introduction of covariates reveals that physical health is indeed an important aspect of mental health, in particular in old age. Accounting for socioeconomic status attenuated the positive association between the number of depressive symptoms and age; only part of the increase observed with age can be 
explained by living arrangements, education and economic situation. The association between age and mental health is mediated by health determinants, especially among women. With the inclusion of health determinants the initially positive association vanishes for men and even turns negative for women, indicating a falling number of depressive symptoms with increasing age. Moreover, the measures for model fit indicate that the differences observed with age are mainly due to physical health (Verropoulou/Tsimbos 2007). Nevertheless, the direction of causality between physical and mental health is not clear.

In the current analysis we first include as covariates socio-demographic characteristics, followed by health conditions. Alternatively, the covariates are introduced in a different order. It turns out that when including first limitations in activities of daily living as well as cognitive orientation and later living arrangements, the results remain stable. Therefore, both aspects - socio-demographic characteristics and health conditions - are independent determinants of mental health, association with the one group not being absorbed by the other.

The unreflected use of gender, or sex, as a technical category is criticised by researchers on gender studies who argue that one must not neglect the substantial differences between being a man and being a woman (Jy/hä 2007). The current study does not include gender as a covariate, but men and women are analysed separately, allowing different associations between the number of depressive symptoms on the one hand, and age as well as socio-economic and health factors on the other. Indeed, the results for age, living arrangements, educational level, economic strain, ADL limitations and chronic diseases differ among men and women, either in size or in direction.

Two limitations have to be mentioned. First, our analysis is based on self-rated health, not on diagnoses by psychiatrists or general practitioners. Regarding the structure of our data, we use a cross-sectional sample, and are therefore not able to disentangle period and cohort effects. As SHARE is designed as a longitudinal study, it will allow us to address this issue in the near future, when several waves are available to the scientific community. What is more, we are not able to investigate dynamic aspects and causalities with our cross-sectional data.

Although the current analysis covers a range of different aspects, other dimensions such as social support, working conditions or transition to retirement are left out. Another potential confounder in the study of the association of age and depressive symptoms in a cross-sectional analysis is the cohort effect (Yang 2007). Moreover, the analysis of the first wave of SHARE does not allow us to detect causalities but only associations.

A compression of morbidity is being observed as Europe ages (Vaupe/ 2010). Due to the increasing relative time spent in good health, the rise in the number of individuals suffering from depression should be less pronounced compared to a situation with prolonged morbidity. This holds true as long as economic strains and socio-demographic characteristics remain constant. 
The authors would like two thank two anonymous reviewers from Comparative Population Studies for important suggestions. The collection of the data was primarily funded by the European Commission through the 5th framework programme (project QLK6-CT-2001-00360 in the thematic programme area "Quality of Life"). Additional funding came from the US National Institute on Aging (U01 AG09740-13S2, P01 AG005842, P01 AG08291, P30 AG12815, Y1-AG-4553-01 and OGHA 04-064). Data collection in Austria (through the Austrian Science Foundation, FWF), Belgium (through the Belgian Science Policy Office) and Switzerland (through BBW/OFES/ UFES) was funded nationally. The SHARE data collection in Israel was funded by the US National Institute on Aging (R21 AG025169), by the German-Israeli Foundation for Scientific Research and Development (G.I.F.), and by the National Insurance Institute of Israel. Further support by the European Commission through the 6th framework program (projects SHARE-I3, RII-CT-2006-062193, and COMPARE, CIT5CT-2005-028857) is gratefully acknowledged.

\section{References}

Adam, Christian 1998: Depressive Störungen im Alter. Epidemiologie und soziale Bedingungen. München: Juventa.

Alonso, Jordi; Angermeyer, Matthias C.; Bernet, Sebastian et al. 2004a: Prevalence of mental disorders in Europe: results from the European Study of Epidemiology of Mental Disorders (ESEMeD) project. In: Acta Psychiatrica Scandinavica 109 (Suppl. 420): 21-27. [doi: 10.1111/j.1600-0047.2004.00327.x]

Alonso, Jordi; Angermeyer, Matthias C.; Lépine, Jean-Pierre 2004b: The European Study of Epidemiology of Mental Disorders (ESEMeD) project: an epidemiological basis for informing mental health policies in Europe. In: Acta Psychiatrica Scandinavica 109 (Suppl. 420): 5-7 [doi: 10.1111/j.1600-0047.2004.00325.x].

Alonso, Jordi; Angermeyer, Matthias C.; Bernet, Sebastian et al. 2004c: Use of mental health services in Europe: results from the European Study of Epidemiology of Mental Disorders (ESEMeD) project. In: Acta Psychiatrica Scandinavica 109 (Suppl. 420): 47-54 [doi: 10.1111/j.1600-0047.2004.00330.x].

Amber, M. Gum; Areán, Patricia; Hunkeler, Enid et al. 2006: Depression Treatment Preferences in Older Primary Care Patients. In: The Gerontologist 46,1: 14-22.

Ayuso-Mateos, Jose Luis; Vázquez-Barquero, Jose Luis; Dowrick, Christopher et al. 2001: Depressive disorders in Europe: prevalence figures from the ODIN study. In: British Journal of Psychiatry 179: 308-316.

Baron, Reuben M.; Kenny, David A. 1986: The Moderator-Mediator Variable Distinction in Social Psychological Research: Conceptual, Strategic, and Statistical Considerations. In: Journal of Personality and Social Psychology 51,6: 1173-1182.

Barry, Lisa C; Allore, Heather G.; Guo, Zhenchao et al. 2008: Higher burden of depression among older women - The effect of onset, persistence, and mortality over time. In: Archives of General Psychiatry 65: 172-178 [doi: 10.1001/archgenpsychiatry.2007.17].

Beck, Aaron T. 1987: Cognitive models of depression. In: The Journal of Cognitive Psychotherapy: An International Quarterly, 1,1: 5-37. 
Beck, Aaron T. 1991: Cognitive therapy: A 30-year retrospective. In: American Psychologist 46,4: 368-375.

Beekman, Aartjan T.F.; Copeland, John R.M.; Prince, Martin J. 1999: Review of community prevalence of depression in later life. In: British Journal of Psychiatry 174: 307-311.

Berkman, Lisa F.; Berkman, Cathy S.; Kasl, Stanislav et al. 1986: Depressive symptoms in relation to physical health and functioning in the elderly. In: American Journal of Epidemiology 3: 372-388.

Blazer, Dan; Burchett, Bruce; Service, Connie et al. 1991: The Association of Age and Depression Among the Elderly: An Epidemiologic Exploration. In: Journal of Gerontology: Medical Sciences 46,6: M210-215.

Börsch-Supan, Axel; Jürges, Hendrik (Eds.) 2005: The Survey of Health, Ageing and Retirement in Europe - Methodology. Mannheim: MEA Eigenverlag.

Braam, Arjan W.; Prince, Michael J.A.; Beekman, Aartjan T.F. et al. 2005: Physical health and depressive symptoms in older Europeans. Results from EURODEP. In: British Journal of Psychiatry 187: 35-42.

Buber, Isabella; Engelhardt, Henriette 2008: Children's impact on the mental health of their older mothers and fathers: finding from the Survey of Health, Ageing and Retirement in Europe. In: European Journal of Ageing 5,1: 31-45 [doi: 10.1007/ s10433-008-0074-8].

Cairney, John; Krause, Neal 2005: The Social Distribution of Psychological Distress and Depression in Older Adults. In: Journal of Aging and Health 17,6: 807-835 [doi: 10.1177/0898264305280985].

Carta, Mauro Giovanni; Bernal, Mariola; Hardoy, Maria Carolina et al. 2005: Migration and mental health in Europe (the state of mental health in Europe working group: appendix I). In: Clinical Practice and Epidemiology in Mental Health. URL: http://www. cpementalhealth.com/content/1/1/13, 26 April 2010 [doi:10.1186/1745-0179-1-13].

Castro-Costa, Erico; Dewey, Michael; Stewart, Robert et al. 2007: Prevalence of depressive symptoms and syndromes in later life in ten European countries. The SHARE study. In: British Journal of Psychiatry 191: 393-401 [doi: 10.1192/bjp.bp.107.036772].

Copeland, John R.M.; Beekman, Aartjan T.F; Dewey, Michael E. et al. 1999a: Depression in Europe. Geographical distribution among older people. In: British Journal of Psychiatry 174: 312-321.

Copeland, John R.M.; Beekman, Aartjan T.F; Dewey, Michael E. et al. 1999b: Crosscultural comparison of depressive symptoms in Europe does not support stereotypes of ageing. In: British Journal of Psychiatry 174: 322-329.

Dean, Alfred; Kolody, Bohdan; Wood, Patricia et al. 1992: The Influence of Living Alone on Depression in Elderly Persons. In: Journal of Aging and Health 4,1: 3-18.

Dewey, Michael E.; Prince, Martin J. 2005: Mental Health. In: Börsch-Supan, Axel; Jürges, Hendrik (Eds.): Health, Ageing and Retirement in Europe - First Results from the Survey of Health, Ageing and Retirement in Europe. Mannheim: MEA Eigenverlag: 108-117. 
Drake, Robert E.; Goldman, Howard H.; Leff, Stephen H. et al. 2001: Implementing Evidence-Based Practices in Routine Mental Health Service Settings. In: Psychiatric Services 52,2: 179-182.

EC (European Commission) 2004a: The State of Mental Health in the European Union. European Commission, Health and Consumer Protection DG. URL: http://ec.europa. eu/health/ph_projects/2001/monitoring/fp_monitoring_2001_frep_06_en.pdf, 26 April 2010.

EC (European Commission) 2004b: Action for Mental Health. Activities co-funded from the European Community Public Health Programmes 1997-2004. European Commission, Health and Consumer Protection DG. URL: http://ec.europa.eu/health/archive/ ph_determinants/life_style/mental/docs/action_1997_2004_en.pdf, 26 April 2010.

EC (European Commission) 2005: Green Paper. Improving the mental health of the population: Towards a strategy on mental health for the European Union. European Commission, Health and Consumer Protection DG, Brussels, 14 October 2005, COM(2005) 484.

Fiske, Amy; Gatz, Margaret; Pedersen, Nancy L. 2003: Depressive Symptoms and Aging: The Effects of Illness and Non-Health-Related Events. In: Journal of Gerontology - Psychological Sciences 58B: P320-328 [doi: 10.1093/geronb/58.6.P320].

Fryers, Tom; Melzer, David; Jenkins, Rachel et al. 2005: The distribution of the common mental disorders: social inequalities in Europe. In: Clinical Practice and Epidemiology in Mental Health. URL: http://www.cpementalhealth.com/content/1/1/14, 25 April 2010 [doi:10.1186/1745-0179-1-14].

Geerlings, Sandra W.; Beekman, Aartjan T.F; Deeg, Dorly J.H. et al. 2000: Physical health and the onset and persistence of depression in older adults: an eight-wave prospective community-based study. In: Psychological Medicine 30: 369-380.

Hamilton, Viviane H.; Merrigan, Phillip; Dufresne, Éric 1997: Down and out: estimating the relationship between mental health and unemployment. In: Health Economics 6,4: 397-406.

Harris, Katherine M.; Edlund, Marc J.; Larson. Sharon L. 2006: Religious involvement and the use of mental health care. In: Health Services Research 41,2: 395-410 [doi: 10.1111/j.1475-6773.2006.00500.x].

Hopcroft, Rosemary L.; Bradley, Dana Burr 2007: The sex difference in depression across 29 countries. In: Social Forces 85: 1483-1507 [doi: 10.1353/sof.2007.0071].

Jang, Yuri; Bergman, Elizabeth; Schonfeld, Lawrence et al. 2007: The Mediating Role of Health Perceptions in the Relation Between Physical and Mental Health. A Study of Older Residents in Assisted Living Facilities. In: Journal of Aging and Health 19,3: 439-452 [doi: 10.1177/0898264307300969].

Jorm, Antony F. 2000: Is Depression a Risk Factor for Dementia or Cognitive Decline? A Review. In: Gerontology 46: 219-227 [doi: 10.1159/000022163].

Jylhä, Marja 2007: Comparisons, cultures, contexts. In: European Journal of Ageing 4,2: 101-102 [doi:10.1007/s10433-007-0051-7].

Kalwij, Adriaan S.; Vermeulen, Frederic 2008: Health and labour force participation of older people in Europe: What do objective health indicators add to the analysis? In: Health Economics 17,5: 619-638 [doi: 10.1002/hec.1285]. 
Katz, Ira R. 1996: On the inseparability of mental and physical health in aged persons Lessons from depression and medical comorbidity. In: American Journal of Geriatric Psychiatry 4: 1-16.

Kessler, Ronald C.; McGonagle, Katherine A.; Zhao, Shanyang et al. 1994: Lifetime and 12-month prevalence of DSM-III-R psychiatric disorders in the United States: Results from the National Comorbidity Survey. In: Archives of General Psychiatry 51: 8-19.

Korten, Ailsa; Henderson, Scott 2000: The Australian National Survey of Mental Health and Well-Being. In: British Journal of Psychiatry 177: 325-330.

Ladin, Keren 2008: Risk of Late-Life Depression Across 10 European Union Countries: Deconstructing the Educational Effect. In: Journal of Aging and Health 2,6: 653-670 [doi: 10.1177/0898264308321002].

Lehtinen, Ville; Michalak, Erin; Wilkinson, Clare et al. 2003: Urban-rural differences in the occurrence of female depressive disorder in Europe - evidence from the ODIN study. In: Social Psychiatry and Psychiatric Epidemiology 38,6: 283-289 [doi: 10.1007/ s00127-003-0631-6].

Lehtinen, Ville; SohIman, Britta; Kovess-Masfety, Viviane 2005: Level of positive mental health in the European Union: Results from the Eurobarometer 2002 survey. In: Clinical Practice and Epidemiology in Mental Health. [http://www.cpementalhealth.com/ content/1/1/9, 25 April 2010] [doi:10.1186/1745-0179-1-9].

Lenze, Eric J.; Rogers, Joan C.; Martire, Lynn M. et al. 2001: The association of late-life depression and anxiety with physical disability: a review of the literature and prospectus for future research. In: American Journal of Geriatric Psychiatry 9: 113-135.

Litwin, Howard 2002: Examination of the association of age, disability, and mood among Jewish older adults in Israel. In: Aging \& Mental Health 6,4: 397-401 [doi: $10.1080 / 1360786021000007018]$.

Litwin, Howard; Sapir, Eliyahu V. 2008: Perceived income adequacy among older adults in 12 countries: Findings from the Survey of Health, Ageing and Retirement in Europe. Hebrew University of Jerusalem, Working Paper.

Long, J. Scott; Freese, Jeremy 2006: Regression Models for Categorical Dependent Variables Using Stata. Texas: Stata Press.

MacKinnon, David P.; Fairchild, Amanda J.; Fritz, Matthew S. 2007: Mediation Analysis. In: Annual Review of Psychology 58: 593-614 [doi: 10.1146/annurev. psych.58.110405.085542].

Mirowsky, John; Ross, Catherine E. 1992: Age and Depression. In: Journal of Health and Social Behavior 33,3: 187-205.

Opolski, Melissa; Wilson, Ian 2005: Asthma and depression: a pragmatic review of the literature and recommendations for future research. In: Clinical Practice and Epidemiology in Mental Health. [doi: 10.1186/1745-0179-1-18], URL: http://www.cpementalhealth.com/content/1/1/18, 20 July 2010.

Prince, Martin J.; Reischies, Friedel; Beekman, Aartjan T.F et al. 1999a: Development of the EURO-D scale - a European Union initiative to compare symptoms of depression in 14 European centres. In: British Journal of Psychiatry 174: 330-38. 
Prince, Martin J.; Beekman, Aartjan T.F; Deeg, Dorly J.H. et al. 1999b: Depression symptoms in late life assessed using the EURO-D scale. Effect of age, gender and marital status in 14 European centres. In: British Journal of Psychiatry 174: 339-45.

Reischies, Friedel M.; Neu, Peter 2000: Comorbidity of mild cognitive disorder and depression - a neuropsychological analysis. In: European Archives of Psychiatry and Clinical Neuroscience 250: 186-193 [doi:10.1007/s004060070023].

Schaan, Barbara 2009: Verwitwung, Geschlecht und Depression im höheren Lebensalter. In: Axe/ Börsch-Supan et al. (Eds.): 50+ in Deutschland und Europa - Ergebnisse des Survey of Health, Ageing and Retirement in Europa [Series 'Alter(n) und Gesellschaft']. Wiesbaden: VS Verlag für Sozialwissenschaften: 115-131.

Scogin, Forrest; Rohling, Martin L. 1989: Cognitive Processes, Self-Reports of Memory Functioning, and Mental Health Status in Older Adults. In: Journal of Aging and Health 1,4: 507-520.

Stephens, Thomas; Joubert, Natacha 2001: The Economic Burden of Mental Health Problems in Canada. In: Chronic Diseases in Canada 22,1: 18-23.

Stordal, Eystein; Krüger, Bjartveit M.; Dahl, Nils H. et al. 2001: Depression in relation to age and gender in the general population: the Nord-Trøndelag Health Study (HUNT). In: Acta Psychiatrica Scandinavica 104,3: 210-216 [doi: 10.1034/j.16000447.2001.00130.x].

Trollor, Julian N.; Anderson, Tracy M.; Sachdev, Perminder S. et al. 2007: Age shall not weary them: mental health in the middle aged and the elderly. In: Australian and New Zealand Journal of Psychiatry 41,7: 581-589 [doi:10.1080/00048670701392817].

Vaupel, James W. 2010: Biodemography of human ageing. In: Nature 464(7288): 536-542 [doi:10.1038/nature08984].

Verropoulou, Georgia; Tsimbos, Cleon 2007: Socio-demographic and health-related factors affecting depression of the Greek population in later life: an analysis using SHARE data. In: European Journal of Ageing 4,3: 171-181 [doi: 10.1007/s10433-007-0060-6].

Winkelmann, Rainer 2003: Econometric Analysis of Count Data. Heidelberg: Springer.

Whooley, Mary A.; Kiefe, Catarina l.; Chesney, Margaret A. et al. 2002: Depressive Symptoms, Unemployment, and Loss of Income: The CARDIA Study. In: Archives of Internal Medicine 162: 2614-2620.

Wittchen, Hans-Ulrich; Jacobi, Frank 2005: Size and burden of mental disorders in Europe - a critical review and appraisal of 27 studies. In: European Neuropsychopharmacology 15,4: 357-376 [doi:10.1016/j.euroneuro.2005.04.012].

Yang, Yang 2007: Is old age depressing? Growth trajectories and cohort variations in late-life depression. In: Journal of Gerontology - Social Science 56B, S311-S320. [doi: 10.1177/002214650704800102]

Zunzunegui, Maria-Victoria; Minicuci, Nadia; Blumstein, Tzuia et al. 2007: Gender differences in depressive symptoms among older adults - A cross-national comparison. In: Social Psychiatry and Psychiatric Epidemiology 42: 198-207 [doi: 10.1007/ s00127-007-0158-3]. 
Translated from the original text by the Federal Institute for Population Research, for information only. The reviewed and author's authorised original article in German is available under the title "Der Zusammenhang zwischen Alter und depressiven Symptomen bei Männern und Frauen höheren Lebensalters in Europa. Erkenntnisse aus dem SHARE-Projekt", DOI 10.4232/10.CPoS2011-02de or URN urn:nbn:de:bib-cpos-2011-02de7, at http://www.comparativepopulationstudies. de.

Date of submission: 28.04 .2010

Date of Acceptance: 17.01.2010

Dr. Isabella Buber-Ennser ( $\varangle$ ). Vienna Institute of Demography (Austrian Academy of Sciences), Wittgenstein Centre for Demography and Global Human Capital,

A-1040 Vienna, Austria.

E-Mail: isabella.buber@oeaw.ac.at

URL: www.oeaw.ac.at/vid

Prof. Dr. Henriette Engelhardt-Wölfler. Chair of Population Studies, Otto Friedrich University Bamberg, 96052 Bamberg, Germany.

E-Mail: henriette.engelhardt-woelfler@uni-bamberg.de

URL: www.uni-bamberg.de/demografie 


\section{Comparative Population Studies - Zeitschrift für Bevölkerungswissenschaft}

wWw.comparativepopulationstudies.de

ISSN: 1869-8980 (Print) - 1869-8999 (Internet)

Published by / Herausgegeben von

Prof. Dr. Norbert F. Schneider

Layout and print: Federal Institute for Population Research, Wiesbaden (Germany)

Managing Editor / Redaktion

Frank Swiaczny

\section{Copy Editor / Schlussredaktion}

Dr. Evelyn Grünheid

\section{Scientific Advisory Board / Wissenschaftlicher Beirat}

Jürgen Dorbritz (Wiesbaden)

Paul Gans (Mannheim)

Johannes Huinink (Bremen)

Marc Luy (Wien)

Clara H. Mulder (Groningen)

Notburga Ott (Bochum)

Peter Preisendörfer (Mainz)

\section{Board of Reviewers / Gutachterbeirat}

Martin Abraham (Erlangen)

Laura Bernardi (Lausanne)

Hansjörg Bucher (Bonn)

Claudia Diehl (Göttingen)

Andreas Diekmann (Zürich)

Gabriele Doblhammer-Reiter (Rostock)

Henriette Engelhardt-Wölfler (Bamberg)

E.-Jürgen Flöthmann (Bielefeld)

Alexia Fürnkranz-Prskawetz (Wien)

Beat Fux (Zürich)

Joshua Goldstein (Rostock)

Karsten Hank (Köln)

Sonja Haug (Regensburg)

Franz-Josef Kemper (Berlin)

Michaela Kreyenfeld (Rostock)

Aart C. Liefbroer (Den Haag)

Kurt Lüscher (Konstanz)

Dimiter Philipov (Wien)

Tomáš Sobotka (Wien)

Heike Trappe (Rostock) 